\title{
Implementation of integrated stepped care for unhealthy alcohol use in HIV clinics
}

\author{
E. Jennifer Edelman ${ }^{1,2^{*}}$, Nathan B. Hansen ${ }^{2,3}$, Christopher J. Cutter ${ }^{1}$, Cheryl Danton ${ }^{1}$, Lynn E. Fiellin ${ }^{1,2}$, \\ Patrick G. O'Connor ${ }^{1}$, Emily C. Williams ${ }^{4,5}$, Stephen A. Maisto ${ }^{6}$, Kendall J. Bryant ${ }^{7}$ and David A. Fiellin ${ }^{1,2}$
}

\begin{abstract}
Background: Effective counseling and pharmacotherapy for unhealthy alcohol use are rarely provided in HIV treatment settings to patients. Our goal was to describe factors influencing implementation of a stepped care model to address unhealthy alcohol use in HIV clinics from the perspectives of social workers, psychologists and addiction psychiatrists.

Methods: We conducted two focus groups with Social Workers $(n=4)$, Psychologists $(n=2)$, and Addiction Psychiatrists $(n=4)$ involved in an ongoing randomized controlled trial evaluating the effectiveness of integrated stepped care for unhealthy alcohol use in HIV-infected patients at five Veterans Health Administration (VA) HIV clinics. Data collection and analyses were guided by the Consolidated Framework for Implementation Research (CFIR) domains, with a focus on the three domains which we considered to be most relevant: intervention characteristics (i.e. motivational interviewing, pharmacotherapy), the inner setting (i.e. HIV clinics), and characteristics of individuals (i.e. the providers). A multidisciplinary team used directed content analysis to identify major themes.
\end{abstract}

Results: From the providers' perspective, the major implementation themes that emerged by CFIR domain included: (1) Intervention characteristics: providers valued tools and processes for facilitating patient motivation for treatment of unhealthy alcohol use given their perceived lack of motivation, but expressed a desire for greater flexibility; (2) Inner setting: treating unhealthy alcohol use in HIV clinics was perceived by providers to be consistent with VA priorities; and (3) Characteristics of individuals: there was high self-efficacy to conduct the intervention, an expressed need for more consistent utilization to maintain skills, and consideration of alternative models for delivering the components of the intervention.

Conclusions: Use of the CFIR framework reveals that implementation of integrated stepped care for unhealthy alcohol use in HIV clinics is facilitated by tools to help providers enhance patient motivation or address unhealthy alcohol use among patients perceived to be unmotivated. Implementation may be facilitated by its consistency with organizational values and existing models of care and attention to optimizing provider self-efficacy and roles (i.e. approaches to treatment integration).

Keywords: HIV, Alcohol-related disorders, Qualitative methods, Diffusion of innovation

\section{Background}

Unhealthy alcohol use, defined as the spectrum of drinking including at-risk drinking and alcohol use disorders [1], is common among HIV-infected patients and

\footnotetext{
*Correspondence: ejennifer.edelman@yale.edu

${ }^{1}$ Yale University School of Medicine, 367 Cedar Street, ESH A, New Haven,

CT 06510, USA

Full list of author information is available at the end of the article
}

associated with a range of adverse health outcomes. Unhealthy alcohol use among HIV-infected patients is associated with poor antiretroviral therapy (ART) adherence [2-8]; impaired treatment response; and decreased quality of HIV care $[5,6,9]$. In turn, individuals who stop drinking experience an improved response to HIV therapy $[5,10]$. Further, unhealthy alcohol use increases the risk of important medical comorbidites, such as 
cardiovascular disease [11], liver disease [12] and malignancy [13] and is associated with sexual risk behaviors and ongoing HIV transmission [14, 15].

\section{Integration of treatment for unhealthy alcohol use into HIV clinics}

Despite the high prevalence and adverse effects of unhealthy alcohol use, few effective interventions for unhealthy alcohol use are offered in HIV clinics [16-21]. Interventions that have been shown to be effective for decreasing unhealthy alcohol use in uninfected patients, including brief interventions for at-risk drinking [22], Motivational Enhancement Therapy, and alcohol pharmacotherapies $[23,24]$ are not routinely provided in HIV clinics $[25,26]$. One advantage of integrating the treatment of unhealthy alcohol use into HIV clinics is that it provides "one stop shopping" and limits potential losses to follow-up seen with referral to off-site treatment. However, integrated treatments are often based on screening strategies and must contend with low levels of knowledge regarding alcohol-associated health risks and motivation among non-treatment seeking individuals $[27,28]$. Also, providers often neglect to discuss or recognize unhealthy alcohol use [29-32] and are underprepared to provide treatment [33]. In addition, treatments for unhealthy alcohol use are not uniformly effective, which provides a rationale for stepped care approaches. Stepped care approaches, which have been applied to chronic disease conditions (e.g. depression and hypertension), typically start with a low-intensity evidence-based intervention with increasing the intensity of treatment if patients fail to respond to initial treatment strategies [34, 35].

\section{The innovation: integrated stepped care for unhealthy alcohol use in HIV clinics}

To address a need for effective treatment models for unhealthy alcohol use among HIV-infected patients through HIV clinics, we are conducting the Starting Ethanol Treatment in Primary care Trial (STEP Trials), a series of three linked multi-site randomized clinical trials designed to evaluate the implementation and effectiveness of integrated stepped care among HIV-infected patients with unhealthy alcohol use. Briefly, HIV-infected patients are recruited into one of three trials based on their alcohol use-(1) at-risk drinking [36], (2) moderate alcohol consumption in the presence of liver disease (MALD) (defined as any alcohol consumption in the past month in the presence of a FIB-4 score greater than 1.45, a validated marker of liver fibrosis [12, 37, 38], or active Hepatitis $C$ virus infection based on serology and presence of a detectable viral load) or (3) alcohol abuse or dependence criteria [39]. Each trial compares integrated stepped care to treatment as usual.

Patients are recruited from one of five Infectious Disease Clinics within the Veterans Health Administration (VA). Patients in the stepped care arm receive evidencebased interventions of increasing intensity (or not) based on their response to initial treatments. Social workers deliver a brief intervention (the Brief Negotiated Interview [BNI]) [40-42] with a two-week telephone booster to patients with at-risk drinking or MALD; Psychologists deliver four sessions of Motivational Enhancement Therapy [43]; and Addiction Psychiatrists provide Addiction Physician Management, with an emphasis on offering pharmacotherapy. Addiction Psychiatrists were encouraged to prescribe pharmacotherapy based on what they thought was most likely to benefit the individual patient. This includes Food and Drug Administration (FDA) approved pharmacotherapies for alcohol dependence (i.e. disulfiram, naltrexone, acamprosate) and prescribing of medications with evidence of efficacy (e.g. topiramate, gabapentin).

To enhance implementation and consistency of the intervention across sites, providers received an initial training and are provided with manuals and structured encountered forms to guide each visit. Providers are also given a "Feedback Form" to review patient-specific data, including self-reported alcohol use, other substance use, level of bother by alcohol use, motivation for treatment, and biomarkers known to be impacted by alcohol [liver function, HCV status, HIV biomarkers, and VACS Index score (a validated prognostic marker of morbidity and mortality found to be responsive to levels of alcohol use)] [44-46] with the patient. Visits with providers occur within the HIV Clinic or nearby available office-space. The STEP Trials is occurring in the context of current VA initiatives focused on developing patient-centered medical homes, known as Patient Aligned Care Teams (PACTs), and its extensions (i.e. Primary Care-Mental Health Integration [PC-MHI] and Health Promotion and Disease Prevention [HPDP] Programs) [47, 48]. These VA programs have been developed to promote the use of multidisciplinary teams to address a range of health related issues in the context of co-located and collaborative care within primary care settings [48].

Consistent with effectiveness-implementation hybrid study designs intended to evaluate a clinical intervention while collecting data on implementation [49], we conducted the current qualitative study to examine perspectives of providers on the implementation of integrated stepped care for unhealthy alcohol use and inform implementation efforts in other HIV clinical settings. Given its suitability for examining factors impacting 
implementation of clinical interventions across different settings and disciplines, including addiction treatment, we used the Consolidated Framework for Implementation Research (CFIR) to guide data collection and a directed content analysis [50-54].

\section{Methods}

Study overview

After approximately 1 year of project implementation and patient care, we conducted two focus groups with Social Workers, Psychologists and Addiction Psychiatrists who were delivering stepped care to address unhealthy alcohol use in HIV clinics in the context of the STEP Trials. We chose qualitative methods given their appropriateness for studying complex processes with regards to patient, physician and organizational-level factors associated with implementation of evidence-based interventions [55]. We used a directed content analysis $[56,57]$ due to its successful use in the past to elucidate implementation efforts according to the CFIR and other implementation science constructs [58-61] (Fig. 1). The protocol was approved by Yale University's Human Investigations Committee and VA Connecticut Healthcare System's Institutional Review Board.

\section{Study design and participants}

While the VA-based healthcare system is an integrated healthcare system, including both primary HIV care and addiction treatment services within the same medical center complex, the level of direct integration of providers into HIV clinics in the context of routine clinical care (i.e. not in the context of the STEP Trials) differs across sites (Table 1). We recruited members of the three types of providers (i.e. Social Workers, Psychologists, and Addiction Psychiatrists) from the five participating HIV clinics who were involved with the STEP Trials. The focus groups were conducted as part of a national meeting whereby participants attended based on availability. None of the potential interventionists declined to participate though some were unable due to their unavailability to travel to the meeting. We chose to conduct focus groups given our expectation that the group interaction

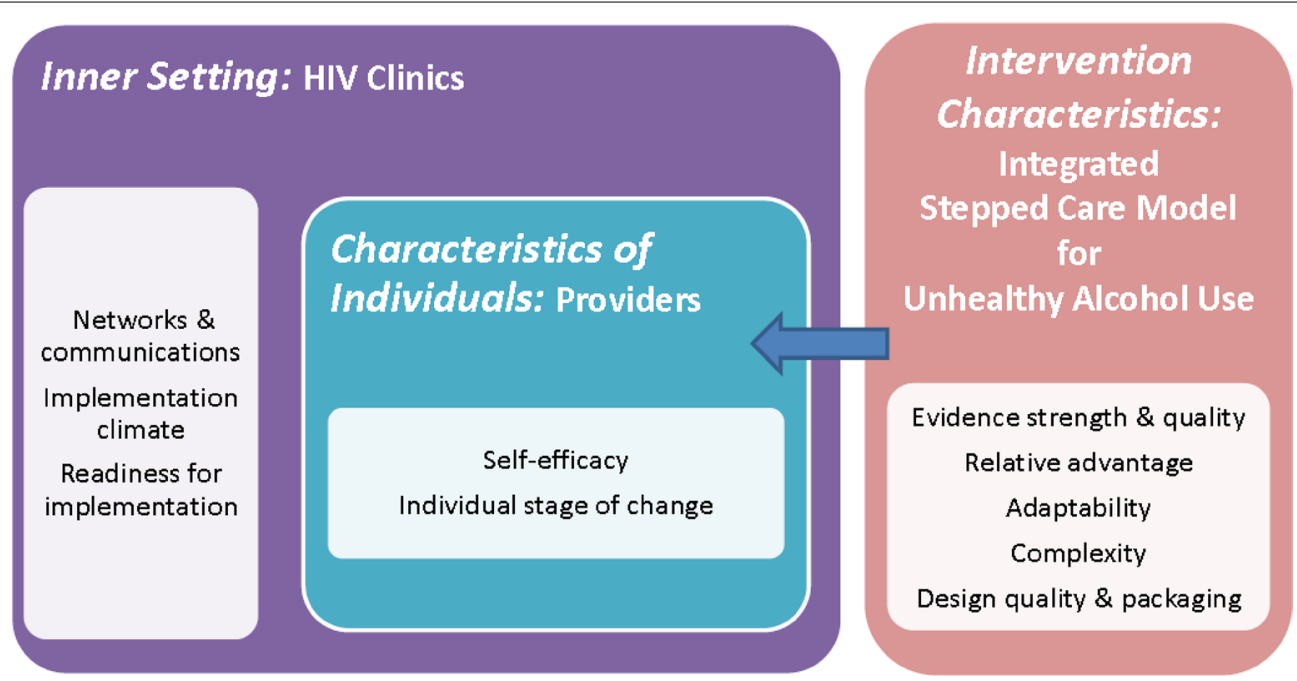

Fig. 1 Integrated stepped care for unhealthy alcohol use in HIV clinics: relevant CFIR domains and constructs*. *Adapted from Damschroder L, Aron DC, Keith RE, Kirsh SR, Alexander JA, Lowery JC. Fostering implementation of health services research findings into practice: A consolidated framework for advancing implementation science. CFIR Figure and Explanatory Text (http://www.implementationscience.com/content/ supplementary/1748-5908-4-50-s1.pdf)

Table 1 Pre-implementation provider integration into HIV clinic and additional considerations by site

\begin{tabular}{lllll}
\hline HIV clinic characteristics & Social worker & Psychologist & Addiction psychiatrist & Additional considerations \\
\hline Site 1 & Yes & No & No & n/a \\
Site 2 & Yes & Yes & No & n/a \\
Site 3 & No & Yes & No & n/a \\
Site 4 & No & No & No & n/a \\
Site 5 & No & No & No & Providers at geographically dispersed VA-based locations \\
\hline
\end{tabular}


would generate unique insights about shared experiences, while also allowing us to learn about differences across sites [55]. All providers gave verbal informed consent and the study was HIPAA compliant.

\section{Data collection}

The two focus groups were facilitated by investigators with experience conducting qualitative research [62-68]. One focus group (facilitated by EJE, DAF, NH and SM) consisted of Social Workers and Psychologists and the other (facilitated by EJE, DAF, LEF) consisted of Addiction Psychiatrists.

\section{Focus group procedures}

Based on the CFIR framework [54] and multi-disciplinary input, we used grand tour questions (i.e. open ended questions intended to stimulate discussion), and probes (i.e. prompts) to examine the perceived impact of intervention characteristics, inner setting and characteristics of the individuals (Fig. 1) on the delivery of integrated stepped care for unhealthy alcohol use in HIV clinics (Text Box) [69]. These CFIR domains were chosen as the focus of this investigation as they were the most directly relevant to the experiences of the providers delivering this innovative intervention and consistent with prior guidance regarding how to apply the CFIR $[54,59]$.

Providers were encouraged to discuss their experience of delivering integrated stepped care in the context of their usual role and not as part of a research project, per se. They were instructed that their responses would be kept confidential, would not impact their current employment or any aspect of involvement in the research. They were also invited to complete a brief demographic survey after the focus groups were completed. The focus groups were recorded, professionally transcribed, and reviewed for accuracy [55].

Text Box: Focus Group Guides: Example Grand Tour Questions with Probes

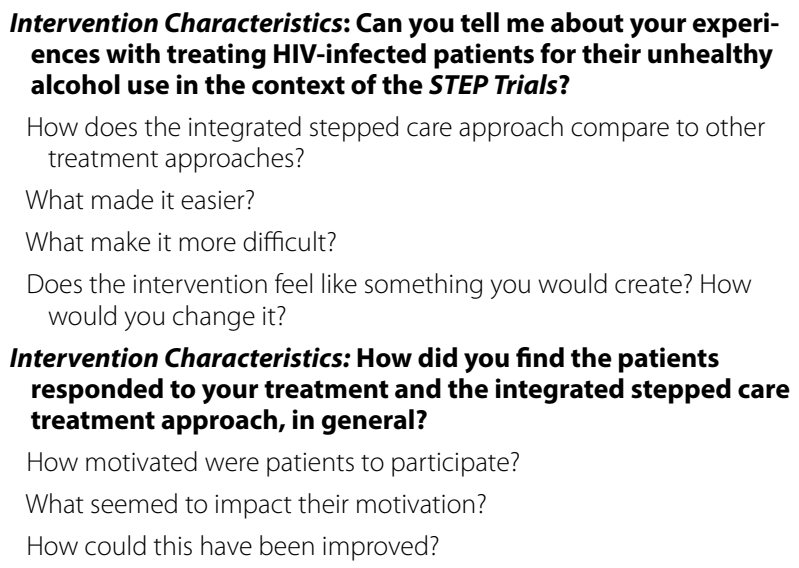

\author{
Characteristics of the Individuals: What was your experience with \\ delivering the intervention? \\ What aspects did you find most effective? \\ What aspects did you find least effective? \\ How did it fit in with your other roles and responsibilities? \\ How comfortable are you in delivering this type of intervention? \\ What changes would you make in the training materials to increase \\ their usability? \\ Inner Setting: Can you tell me more about how you communicated \\ with others involved in the care of your patients with unhealthy \\ alcohol use? \\ What about social workers/psychologists/psychiatrists? \\ What about the patients' primary care provider?
}

Inner Setting: How important is treating unhealthy alcohol use to your supervisor? To the VA?

Does this get measured in any way?

What kinds of resources are dedicated to this?

Do you think your supervisor would support you to do this kind of work even after the trial ends?

Describe some of the complexities in implementing this treatment model with regards to the duration, scope, disruption of other activities, number of steps.

Grand tour questions in bold; CFIR constructs noted in bold with italics

\section{Qualitative analysis}

Six individuals of our multidisciplinary team, including members not present at the focus groups and one member not previously involved in the project, applied content analysis with a deductive approach to code the transcripts $[56,57]$. Team members were trained on the CFIR framework [54] in advance and used the domains and constructs as predetermined codes [52]. The transcripts were independently reviewed line by line, and elements of the CFIR domains and constructs were assigned to meaning units (i.e. transcript text) [57]. Team members met to discuss emerging ideas, resolve discrepancies and reach consensus regarding the codes. One author (EJE) then re-reviewed the transcripts to systematically apply these codes. To organize the data and facilitate retrieval, we used qualitative analysis software (AtlasTi version 6.2, Berlin, Germany). We organized the transcript text by domains and constructs and then re-reviewed the quotes for themes and illustrative text and discussed as a group. To increase the rigor of our approach, we reviewed a summary of our findings with participants to confirm that we had accurately understood and conveyed their experiences [55].

\section{Results}

Participating providers included Social Workers $(\mathrm{n}=4)$, Psychologists $(\mathrm{n}=2)$ and Addiction Psychiatrists $(\mathrm{n}=4)$ (Table 2). We present themes and representative quotes organized by the CFIR domains and their sub-domains, 
Table 2 Relevant CFIR Domains with definitions as applied to integrated stepped care for unhealthy alcohol use

\begin{tabular}{|c|c|}
\hline Domain & Definition \\
\hline \multicolumn{2}{|c|}{ I. Intervention characteristics: integrated stepped care for unhealthy alcohol use } \\
\hline Evidence strength \& quality & $\begin{array}{l}\text { Providers' perception of the quality and validity of evidence supporting the belief that integrated stepped care } \\
\text { for unhealthy alcohol use will lead to decreased unhealthy alcohol use }\end{array}$ \\
\hline Relative advantage & $\begin{array}{l}\text { Providers' perception of the advantage of implementing integrated stepped care for unhealthy alcohol use } \\
\text { versus an alternative solution }\end{array}$ \\
\hline Adaptability & $\begin{array}{l}\text { The degree to which integrated stepped care for unhealthy alcohol use can be adapted, tailored, refined, or } \\
\text { reinvented to meet local needs }\end{array}$ \\
\hline Complexity & $\begin{array}{l}\text { Perceived difficulty of implementation, reflected by duration, scope, radicalness, disruptiveness, centrality, and } \\
\text { intricacy and number of steps required to implement }\end{array}$ \\
\hline Design quality \& packaging & $\begin{array}{l}\text { Perceived excellence in how integrated stepped care for unhealthy alcohol use is bundled, presented, and } \\
\text { assembled }\end{array}$ \\
\hline \multicolumn{2}{|l|}{ II. Inner domain: HIV clinics } \\
\hline Networks and communications & $\begin{array}{l}\text { The nature and quality of webs of social networks and the nature and quality of formal and informal communi- } \\
\text { cations within VA-based HIV clinics and across providers }\end{array}$ \\
\hline Implementation climate & $\begin{array}{l}\text { The absorptive capacity for change, shared receptivity of involved individuals to integrated stepped care for } \\
\text { unhealthy alcohol use and the extent to which use of it will be rewarded, supported, and expected within the } \\
\text { VA }\end{array}$ \\
\hline Tension for change & The degree to which providers perceive the current situation as intolerable or needing change \\
\hline Compatibility & $\begin{array}{l}\text { The degree of tangible fit between meaning and values attached to integrated stepped care for unhealthy } \\
\text { alcohol use by involved individuals, how those align with individuals' own norms, values, and perceived risks } \\
\text { and needs, and how this treatment model with existing workflows and systems }\end{array}$ \\
\hline Relative priority & Individuals'shared perception of the importance of the implementation within the VA-based HIV clinics \\
\hline Readiness for implementation & $\begin{array}{l}\text { Tangible and immediate indicators of organizational commitment to its decision to implement integrated } \\
\text { stepped care for unhealthy alcohol use }\end{array}$ \\
\hline Available resources & $\begin{array}{l}\text { The level of resources dedicated for implementation and on-going operations, including money, training, educa- } \\
\text { tion, physical space, and time }\end{array}$ \\
\hline $\begin{array}{l}\text { Access to knowledge \& informa- } \\
\text { tion }\end{array}$ & $\begin{array}{l}\text { Ease of access to digestible information and knowledge about the intervention and how to incorporate it into } \\
\text { work tasks }\end{array}$ \\
\hline \multicolumn{2}{|l|}{ III. Characteristics of individuals: providers } \\
\hline Self-efficacy & Providers' belief in their own capabilities to execute courses of action to achieve implementation goals \\
\hline Individual stage of change & $\begin{array}{l}\text { Characterization of the phase a provider is in, as he/she progresses toward skilled, enthusiastic and sustained use } \\
\text { of integrated stepped care for unhealthy alcohol use }\end{array}$ \\
\hline
\end{tabular}

Adapted from Damschroder LJ, Aron DC, Keith RE, Kirsh SR, Alexander JA, Lowery JC. Fostering implementation of health services research findings into practice: A consolidated framework for advancing implementation science. CFIR Constructs with Short Definitions (http://www.implementationscience.com/content/ supplementary/1748-5908-4-50-s3.pdf)

\section{Table 3 Provider characteristics}

\begin{tabular}{lllll}
\hline Characteristic & Overall $(\mathbf{n}=\mathbf{9})$ & Social workers $(\mathbf{n}=\mathbf{4})$ & Psychologists $(\mathbf{n}=\mathbf{2})$ & Addiction psychiatrists $(\mathbf{n}=\mathbf{3})$ \\
\hline $\begin{array}{l}\text { Age, mean (SD) in years } \\
\text { Race (\%) }\end{array}$ & $44(11)$ & $35(8)^{*}$ & $54(1)$ & $45(11)$ \\
White & 78 & 100 & 50 & 67 \\
Black & 11 & 0 & 50 & 0 \\
Asian & 11 & 0 & 0 & 33 \\
Ethnicity, Hispanic (\%) & 11 & 25 & 0 & 0 \\
Gender, Female (\%) & 89 & 100 & 100 & 67 \\
Average number weekly patients, mean (SD) & $23(20)$ & $20(18)$ & $23(18)$ & $29(29)$ \\
$\quad$ Number HIV-infected, mean (SD) & $8(11)$ & $15(14)$ & $2(1)$ & $17(14)$ \\
Number with an alcohol use disorder or alcohol $12(12)$ & $5(5)$ & $16(20)$ & $14(10)$ \\
$\quad$ related problem, mean (SD) & $8(8),[1-24]$ & $5(7),[1-15]$ & $6(4),[3-9]$ & \\
Years in current role, mean (SD), [range] &
\end{tabular}

One social worker did not provide data on age and focus groups included one additional Addiction Psychiatrist who declined to complete the survey; thus these data are missing 
with a focus on intervention characteristics, the inner setting, and characteristics of the individuals. The definitions used for each domain and sub-domain as applied to the STEP Trials are listed in Table 3.

\section{Intervention Characteristics Domain: Integrated Stepped Care Model}

Providers indicated that the integrated stepped care model quality, content and packaging facilitated implementation, yet believed it would benefit from adaptability with regards to content, duration and source of the intervention.

\section{Evidence strength and quality}

Social Workers and Psychologists, alike, endorsed fundamental aspects of the intervention, such as motivational interviewing, and recognized that it was evidence-based and believed it to be of high quality. For example, one provider described:

I come from an addiction background before coming to the Infectious Disease clinic, and my mental health background. So motivational interviewing is kind of like magic dust...

Similarly, the Addiction Psychiatrists were familiar with strong data supporting the use of pharmacotherapy to treat alcohol use disorders as recommended within the stepped care model:

I was thinking about the COMBINE Study and the medical management was a very powerful intervention. I recall from Project COMBINE that included recommendations of going to $A A$, but it also included me prescribing medication.

\section{Relative advantage}

As participants were often not treatment seeking, the providers found it helpful that the intervention contained tools, such as personalized normative feedback, for promoting motivation:

The one where it talked about your drinking [compared to norms], in both my cases they were surprised by the results. It was palpable. You could tell. They... you know. What do you think of what I've just said in terms of, this shows there is such-this high percentile [compared to] drinking [norms] the language is-was surprising to them.

\section{Adaptability}

Providers reported a desire for increased flexibility regarding the number of treatment sessions, as well as an ability to expand the scope of the focus to address other prevalent and important risk behaviors. On one hand, they felt that more time was needed to effectively build rapport and expressed a desire to be able to tailor the number of treatment sessions to participant needs. On the other hand, there was an expressed preference to maintain the treatment number as finite. For example, one Psychologist reported:

The one thing I probably would change, I think I would want more than, maybe just a little more than four sessions, for me... My guys worked, so we had to kind of shuffle around to get 'em in on off days, so committing to 4 sessions was easy. But I felt like they-you were just at that point where you're holding your kids' hips as he's bicycling without training wheels and I just let him go, and he was just taking off-Session number 4. Done. And if I only had just a 5th, maybe just a 5th session, would be the one thing that I would change. . . [But] I'm all for. . . therapy ending.

Similarly, one Addiction Psychiatrist echoed these sentiments:

.. you start to build a [rapport], and then, because of this session slots issue you cannot see him anymore.

Providers were also eager to extend the intervention to address drug use in addition to alcohol use:

The only other thing too that I also thought about in terms of I think all of our patients, we're only focusing on alcohol use... we have like a huge crack epidemic too. . . So it's also interesting to me that we're only talking to them about how alcohol impacts their body, and I'm ignoring the fact. . . he's like, "No, I did not drink, I just smoked crack yesterday." Great. You know.

In addition, there was a stated interest by one Social Worker to extend the focus from impact on health to HIV prevention efforts:

I mean, talking about the relationship between your sex practices and your substance use, talking about the relationship between lack of condom use and substance use, that's all huge in our clinic. There's a huge correlation between that. Even to asking them about, are you disclosing your sex-when they go to sex parties, there's a whole, that's a whole 'nother-... I would totally be interested in seeing how we could do best practices in the VA with prevention positives.

\section{Complexity}

Some aspects of integrated stepped care for unhealthy alcohol use were perceived to be complex. Identifying appropriate individuals for the intervention was among the greatest challenges. Providers expressed a need for 
clear processes for identifying HIV-infected individuals with unhealthy alcohol use:

Yeah, unless you had, when they come to the clinic, you provide them with a packet of paperwork for them to fill out, and you have the AUDIT-C or whatever other screening tools you're using, I think it's going to be difficult to implement.

Other challenges with implementation of the intervention included the time involved as well as management of the logistics. It was felt that dedicated staffing was needed to manage the logistics involved with intervention implementation. According to one Social Worker:

Somebody would have to be tracking to make sure that it went the right way. There's gotta be a way... in terms of tracking someone would have to be responsible for it. It might be unrealistic to think that with 1100 or 1500 person caseloads, a Social Worker would really be able to do that well. I mean, things would fall through the cracks.

With regards to the time involved in delivering the intervention, one Social Worker reflected on the complexity of implementing the intervention with regards to time and logistics:

I think the word "brief" can be deceiving sometimes... I don't think that 20 min which I think was the original design was always necessarily [enough time]- I think sometimes it drags out more so to 40 something to really bring 'em around. And then the phone booster depending on, same thing, like the resource needs, can be a challenge. And in my real world I think scheduling a phone appointment, if it's not [the research coordinator] reminding me that I have to do the phone appointment, and me finding it on my Outlook is challenging, just because I have walk-in clinics.

This contrasted with overall sentiments that the intervention required less time and effort than initially anticipated given participant flow as described by another social worker:

...it's not like we're seeing this huge amount of patients. But I think that when you're presenting it to people... it'd be helpful to kind of inform them of that up front... but it's not that big of a workload difference.

\section{Design quality and packaging}

The providers reported that the intervention packaging provided useful and novel tools for facilitating alcoholrelated discussions:
Social Worker 1: This is more structured, I didn't have readiness tools and things like that, but, which are great.

Social Worker 2: I also like the feedback tool, because we don't always have like their levels right in front of us, I mean we can obviously click through the whole chart and look at all of their labs... So it puts it in a nice neat package in terms of providing them with the feedback and having all the normative data and everything else.

These sentiments were shared by the Psychologists:

Psychologist 1: One, we sent them home with a sort of a homework form [and we said, bring it back]. I think that has the effect in some ways of sort of holding them accountable, when you have to write down what you've done. Write your sins down.

Psychologist 2: In my experience, the feedback form was absolutely helpful, and because it allowed them to-both of them to, whether they wanted to see how much they were drinking or not, and related it to specific incidents, that allowed them to see those triggers.

Providers felt that the initial packaging would be improved with more accurate representation of the impact on workflow. As described by one Social Worker:

I think you can-just by acknowledging, "you're probably already using these, and you're probably already doing this, we just want to give you a format and kind of keep track of it." Because you're not indicating that you're adding any more work on... So you're not adding on anything more on their caseloads. Especially like if you're doing it within the ID clinic, and the social workers within the clinic are already meeting with these patients. So, I think it's just acknowledging that.

In addition to recommendations regarding how the intervention is packaged to the providers, there was a perceived need for additional patient-centered materials as it related to communicating about pharmacotherapy treatment options:

For some of my patients, not just in the trial, they've had prior experience with disulfiram. And they don't want to go there. And they lump all the medicines together into I'm talking to them about disulfiram. It doesn't matter what I say, it's just like the Charlie Brown, waw waw, waw waw, waw waw. They thinking in their mind, disulfiram, if I slip up I'm going to get sick and die, I can't take medication. It would be nice to have like a table or something to say, "This is this medicine, it's what it does; this is this medicine, 
this one's different"...

\section{Inner Setting Domain: HIV Clinics}

Addressing unhealthy alcohol use was compatible with norms, values, and basic assumptions of the VA, and integrated care was compatible with VA priorities (i.e. creating a medical home) but implementation seemed to be affected by networks and communication, the implementation climate and readiness for implementation.

\section{Networks and communications}

Providers reported that communication among those providers who were co-located in HIV clinics was strong and this facilitated implementation of the intervention. For example, there was fluid and ongoing communication between ID providers and Social Workers:

\section{And the doctors refer as they're seeing patients that have the social work-related concerns, as needed.}

Among providers who were not traditionally based in the clinic, however, there was an expressed need for tighter links of communication. As one Addiction Psychiatrist stated:

One thing I would like is... a local call-a local meeting-that would be very helpful too. See what's going on... It would be nice to hear what's going on.

This was also noted by the Social Workers regarding communication with the Addiction Psychiatrists:

Social Worker 1: I know we're all only a phone call away but we don't-also if you have elevators at that level where they're seeing the addiction psychiatrist, they're not necessarily having contact with us anymore, so there's not that communication on that level.

Social Worker 2: Oh yeah, we work as a team. I knock on their door, they knock on my door, no, we definitely work as a team, except, the same thing, the addiction psychiatrist is in a separate part of-you know, our building is very large.

\section{Implementation climate}

Aspects (i.e. sub-domains) of the implementation climate most impacting the implementation climate included the tension for change, compatibility, and relative priority.

\section{Tension for change}

There was a recognized need for integrated addiction services. As described by one of the Addiction Psychiatrists:

That's something if a position can be carved out... and there is a need. There is such a need. Because I get so many phone calls.

Similarly, developing effective models for treating unhealthy alcohol use were recognized as a priority among VA leadership, with a current focus on specialty settings:

I would say we'd be supported at the national level. . . But right now, frankly our challenge is gettingwhere we've been focusing our energy is getting the specialty programs to prescribe medication for alcohol dependence or use disorders. The uptake is really low, nationally.

\section{Compatibility}

The Social Worker-based intervention (i.e. the BNI and booster) was highly consistent with ongoing efforts:

\section{It's basically what we-I mean, at least me, what I have been doing.}

Social Workers who pre-implementation were embedded into the HIV clinics (see Table 1) conduct comprehensive assessments, which typically include an evaluation of alcohol use, as part of routine care promote compatibility of the intervention:

The way that we operate is, I see all of our new patients ideally like when either they're newly diagnosed [with HIV] or new to our clinic. Ideally before their initial physician's appointment, when they come in and get their initial lab work done? I see them, do a comprehensive bio-psychosocial assessment, and or provide like post-HIV diagnosis counseling, and then see them as needed from there on out, depending on what their resource needs are and psychosocial stressors. And the patients that are long established, I see them either when they come as a walk-into see me because they need something, or because the doctors think that they need to see me, or the nurse or the pharmacist or whomever in the clinic.

The structure was consistent with the PACTs:

I think it would be a great... the PACT teams all have now a social worker, a nurse. I think that would be where. . And everybody's supposed to have a primary care. Should be assigned a primary care. So I think adding this [intervention] in that team, would be. . you would catch the majority of people.

The intervention was also thought to be consistent with ongoing efforts to promote integrated services:

So they would be more integrated and they would work more like a team, as opposed to being a group 
practice of independent providers which is how most mental health clinics are now. And so they've been rolling this out for about a year or so, and part of what they've talked about is how would you integrate addiction treatment into that.

\section{Relative priority}

Addressing unhealthy alcohol use was a priority, particularly when it related to HIV-related outcomes, but one of many priorities:

But we still, like even before this study I was gonnawe used this framework. You know, when you're dealing with somebody who's, for example, you go into one of the [clinic] meetings and they're not taking their HIV meds like they're supposed to, and they're developing all this resistance and one of the identified reasons is alcohol, I call them in, talk to them and then hopefully it leads to a referral. . . but as our role as social workers to the clinic we'd be neglecting a lot of the other important information if we solely focused on the alcohol without addressing all of the other psychosocial stressors and concerns.

\section{Readiness for implementation}

Aspects (i.e. sub-domains) most impacting readiness for implementation included available resources and access to knowledge and information.

\section{Available resources}

In reflecting about potential providers that might be appropriate for delivering the intervention, nurses were not believed to be appropriate:

We have nurses but our nurses are really directed in nature versus like looking at a framework. This is a lot more probing, and our nurses are much more prescriptive and directive in nature. I don't know if that's across the board though.

\section{Access to knowledge and information}

There was a perceived need to raise awareness and educate important stakeholders, including patients and HIV providers alike, about pharmacotherapy. As one Addiction Psychiatrist described:

But something, I mean it makes sense-pharmaceutical companies don't just create something and publish some papers and let it go at that. In order to get people to uptake it they do proactively go out and detail. So we really shouldn't be surprised if we publish a paper and people don't uptake it either. . if we could convince the ID docs to at least initiate it, to talk about naltrexone a little bit, and maybe we don't have to burden them with managing it. But if we could get them to just sell it a little better.

Other Addiction Psychiatrists also commented on their challenges with initiating pharmacotherapy to treat alcohol use disorders:

Addiction Psychiatrist 1: One guy came almost every session. Unfortunately he just said, "I like to talk to you, not like to take medicine from you." Addiction Psychiatrist 2: I have been more successful prescribing SSRI's and [tricylics rather than acamprosate]. There's a fair bit of resistance [to pharmacotherapy]. .. It's like, some of-a good number of them have been in AA, so you don't need a pill-it's-anything. That resistance, I don't know-I don't need a pill to-I can do it on my own. A lot of patients, it's from the AA end. And probably some of the pressure is also from... their primary care docs or their cardiologists have never thought about naltrexone.

\section{Characteristics of Individuals Domain: Providers (i.e. Social Workers, Psychologists and Addiction Psychiatrists)}

Providers endorsed high self-efficacy regarding their implementation, but voiced a need for more consistent utilization of the intervention to maintain skills and discussed alternative models and roles for delivering the components of the intervention.

\section{Self-efficacy}

One Social Worker expressed her enthusiasm for the intervention and comfort with implementing the intervention:

I'd be seeing them anyways. And so I'm glad to know that you have educated me, and it fits. It definitely fits with what we're doing.

This provider attributed treatment success to be most related to the participants and did not attribute it to her treatment or the intervention:

I think level of engagement has something to do with it. When we talked, I-the first client that I had was just so into it that by the time the second session, he was way ahead, way ahead, and so all I could do was affirm what he was doing.

Low patient volume necessitated relearning of materials. One Psychologist stated:

And there's too much time in between [patients]. It's almost like having to relearn it every [time]. 


\section{Individual stage of change}

Whether HIV providers should be responsible for delivering components of the intervention (e.g. the BNI) was questioned by a Social Worker and Addiction Psychiatrist. As described by one Social Worker:

But if it's such a brief thing, and they already have a relationship with their physician, doesn't it make sense to have the physician do this, and then they have the MET with a social worker, I feel like most social workers that I come cross in the VA, could probably do the MET [stuff].

One Addiction Psychiatrist also agreed that the HIV provider would be effective at delivering pharmacotherapy:

\section{I think that it could also be powerful if the medica- tion was coming from the Infectious Disease doc, the person who saved my life saying, I think it's impor- tant for your health and your management of your $H I V$ disease, that you stop drinking, and I'm willing to work with you...I do think that there's something powerful when the doc who's saved your life says, "I think you should do something." That carries a lot of weight. As opposed to this other person I referred you to. So that would be my only suggestion. But I don't know if you could get ID docs to... I would submit that they have great motivational skills, because if they can get folks to take HIV meds, then they know how to motivate people.}

\section{Discussion}

Focusing on three CFIR domains, we examined factors impacting the implementation of a model of stepped care for unhealthy alcohol use in HIV clinics. Based on the experiences of Social Workers, Psychologists and Addiction Psychiatrists from five different clinics, several factors emerged as deserving careful consideration for future implementation efforts. First, the providers deemed patients as not typically seeking treatment, and thus materials and processes for facilitating patient motivation for treatment of their unhealthy alcohol use were key and should have greater flexibility. Second, treating unhealthy alcohol use in HIV clinics was perceived by providers to be consistent with VA priorities, which are focused on both screening for and intervening upon unhealthy alcohol use and promoting medical home models of care. Third, depending on the existing role of the provider, there was variability in the perceptions regarding the ideal model for promoting integrated care. These data represent a novel contribution to the literature as they shed light on important factors deserving consideration in implementation of a stepped care model for unhealthy alcohol use in HIV clinics and identify actionable opportunities for future implementation efforts.

Because HIV-infected patients with unhealthy alcohol use were generally not seeking treatment, an advantage of the integrated stepped care model included the tools and process which facilitated patient motivation for treatment. Prior work has demonstrated that HIVinfected patients drink to cope with negative emotions, to promote social interactions, and in response to social pressure [28]; these motivations might be a barrier to treatment. The design of the integrated stepped care model (i.e. Social Worker and Psychologist-delivered manualized counseling focused on enhancing patient motivation to change their alcohol consumption and structured, personalized feedback for patients) facilitated its implementation. While the providers found these techniques to be familiar, they found that the integrated stepped care model provided them with new techniques and materials for enhancing patient motivation, which they perceived to be a barrier to promoting treatment. Indeed, these tools may serve to reinforce motivations to decrease alcohol consumption that have been previously identified as reasons that HIV-infected patients limit their drinking (i.e. concerns about the impact of alcohol use on social functioning, lifestyle incompatibility and physical and mental functioning) [70].

Importantly, treating unhealthy alcohol use through clinic-based settings was perceived by providers to be consistent with VA priorities. Specifically, there have been extensive efforts to promote evidence-based AUDIT-C screening followed by appropriate intervention (i.e. brief intervention, specialty care) for unhealthy alcohol use across VA settings [71, 72]. In contrast, uptake of evidence-based pharmacotherapy for alcohol use disorders has been slow [73-75] despite VA guidelines supporting the use of pharmacotherapy [76]. Addiction Psychiatrists generally recognized accessible pharmacotherapy as an important treatment option for alcohol use disorders, yet reported variable success in initiating treatment. This suggests that patient and HIV providertargeted education and marketing may be important for improving uptake among non-treatment seeking individuals in the setting of shared-decision making after consideration of all available treatment options [77].

Furthermore, providers found that the integrated stepped care model was consistent with VA priorities given recent initiatives to develop and evaluate new models for delivering screening and treatment for unhealthy alcohol use. Providers also perceived the integrated stepped care model as consistent with PACT as well as PC-MHI and HPDP initiatives, which has important implications for potential future scalability. Such models 
tend to promote improved communication and tighter networks and allow for flexibility in session duration and specific content, as desired by providers in this study.

While providers were consistent in their reported beliefs that the integrated stepped care model offered a high quality intervention, there were differences based on provider experience and type regarding the ideal way in which to integrate treatment of unhealthy alcohol use into HIV clinics. For example, while some Social Workers believed it was ideal for social workers to deliver the BNI, other suggested that either Infectious Disease Physicians or nurses might provide these services. Additionally, they felt they had the requisite skills and experience to provide the MET intervention. Similarly, it was suggested by Addiction Psychiatrists that Infectious Disease Physicians might be best positioned to engage patients in treatment for unhealthy alcohol use. That a tension exists regarding how to best integrate services is not surprising. On one hand, Infectious Disease and HIV-specialty trained physicians, who increasingly serve as the primary care physician for HIV-infected patients, have an existing relationship with the patient and are managing other treatments. However, prior multi-site studies indicate that HIV providers are often unaware of their patient's alcohol use and often do not discuss it, even with patients with higher levels of drinking [29, 30, 78]. Moreover, only $65 \%$ of HIV providers reported high comfort with discussing substance use [32]. Thus, it is likely that team-based approaches as structured in the integrated stepped care model, which do not rely on HIV providers to deliver treatment for unhealthy alcohol use, are likely to be an important strategy for effectively addressing unhealthy alcohol use. This model is consistent with others developed to treat other substance use disorders (i.e. buprenorphine for opioid use disorders in HIV clinics) [79-81] and supports the integration of social workers, Psychologists and Addition Psychiatrists into HIV clinics. If effectiveness of integrated stepped care for unhealthy alcohol use in HIV clinics is demonstrated, future studies should focus on determining the optimal role of HIV providers, based on their knowledge and self-efficacy, for delivering such treatments. In addition, the extent to which such an intervention should target other health behaviors, such as drug use or sexual risk behaviors, warrants investigation.

The results of this study should be interpreted in the context of its limitations. First, the providers represented a convenience sample of individuals involved with an ongoing randomized controlled trial. Our results may not reflect the opinions of other providers involved with the randomized controlled trial or apply to other VA-based providers more generally. Second, our interview guides were not piloted in advance of our study. In retrospect, given the expressed need to address alcohol along with other drug use and HIV prevention, we would have asked Addiction Psychiatrists further about their comfort prescribing pharmacotherapy for other substances (i.e. tobacco, opioids, cocaine) using an integrated model and how they might address HIV risk behaviors and prevention. Third, these findings may not transfer universally to other HIV clinical settings, particularly settings where Psychologists and Addiction Psychiatrists are less available. The goal of the STEP Trials is to evaluate the effectiveness of integrated care from Psychologist and Addiction Psychiatrists, along with Social Workers. If effectiveness is demonstrated, issues of generalizability of this and the main study's findings to other HIV clinical settings will be carefully considered. Fourth, this qualitative study was conducted during the 1st year of implementation of integrated stepped care in the context of a randomized controlled trial. Whether these findings will apply at later stages is unclear; though this study does provide important insights to inform planning phases and initial implementation of integrated stepped care models. Fifth, given our small sample size, we are unable to determine whether we had reached thematic saturation. Regardless, this study provides meaningful data given its focus on implementation of a novel model of care for unhealthy alcohol use in HIV clinics based on a robust deductive approach to data analysis, which revealed consistency in findings within and across different groups of providers. Sixth, our study may have been subject to social desirability bias given the proportion of interviewers relative to interventionists; however, we felt that the diverse perspectives of the interviewers served to enhance the richness of the conversation and data collection.

\section{Conclusions}

In conclusion, our study represents an important step in identifying key considerations based upon the CFIR constructs when implementing an integrated stepped care model for unhealthy alcohol use in HIV clinics. We found that implementation of this model may be facilitated by tools to help providers enhance patient motivation, close alignment with organizational values and existing models of care, and optimization of provider self-efficacy and roles. Future efforts aimed at obtaining the perspectives of additional providers, as well as patients and HIV providers will be important for developing a comprehensive understanding of factors impacting implementation of integrated stepped care for unhealthy alcohol use in HIV clinics. In addition, consideration of alternative models involving various providers completing the primary components of the intervention, will be important for informing the development of successful interventions. 


\section{Authors' contributions}

EJE participated in all aspects of this study, including writing the HIC protocol, leading the data analysis and writing the first draft of the manuscript. NBH and SAM contributed to design of the data collection tools, participated in data collection and analysis. CD contributed to the design of the data collection tools and data analysis. LEF participated in data collection. PGOC and ECW participated in data analysis. DAF participated in all aspects of this study, including conceiving the study design, leading the data collection, and revising of the manuscript. All authors made substantial contributions to the revising of the manuscript. All authors read and approved the final manuscript.

\section{Author details}

${ }^{1}$ Yale University School of Medicine, 367 Cedar Street, ESH A, New Haven, CT 06510, USA. ${ }^{2}$ Center for Interdisciplinary Research On AIDS, Yale University School of Public Health, 135 College Street, New Haven, CT 06510, USA. ${ }^{3}$ College of Public Health, University of Georgia, 131 Wright Hall, Health Sciences Campus, Athens, GA 30602, USA. ${ }^{4}$ VA Puget Sound Health Care System, Center of Innovation for Veteran-Centered and Value-Driven Care, 1100 Olive Way, Suite 1400, Seattle, WA 98101, USA. ${ }^{5}$ Department of Health Services, University of Washington, 1959 NE Pacific Street, Magnuson Health Sciences Center, Room H-664, Seattle, WA 98195, USA. ${ }^{6}$ Syracuse University, 430 Huntington Hall, Syracuse, NY 13244, USA. ${ }^{7}$ National Institute on Alcohol Abuse and Alcoholism HIV/AIDS Program, 5635 Fishers Lane, Bethesda, MD 20892-7003, USA.

\section{Competing interests}

The authors declare that they have no competing interests.

\section{Funding}

This work was generously supported by grants from the National Institute on Alcohol Abuse and Alcoholism (NIAAA) (1U01AA020795, 2K05 AA16928) and the National Institute on Drug Abuse (NIDA) (K12DA033312-02). Dr. Williams is supported by a Career Development Award from VA Health Services Research \& Development (CDA 12-276) and is an investigator with the Implementation Research Institute (IRI) at the George Warren Brown School of Social Work at Washington University in St. Louis. IRI is supported through an award from the National Institute of Mental Health (R25 MH080916-01A2) and the Department of Veterans Affairs, Health Services Research \& Development Service, Quality Enhancement Research Initiative (QUERI). Neither NIH nor the VA had a role in the study design; in the collection, analysis and interpretation of data; in the writing of the report; and in the decision to submit the article for publication. Dr. Kendall Bryant, a NIAAA employee and scientific collaborator on the project, participated in the analysis and interpretation of data; in the writing of the report; and in the decision to submit the article for publication.

\section{Disclosures}

Earlier versions of this work were presented as poster presentations at the 38th Annual Research Society on Alcoholism Scientific Meeting on June 24, 2015 in San Antonio, Texas and the 8th Annual Conference on the Science of Dissemination and Implementation on December 15, 2015 in Washington, D.C.

Received: 8 May 2015 Accepted: 23 December 2015

Published online: 13 January 2016

\section{References}

1. Saitz R. Clinical practice. Unhealthy alcohol use. N Engl J Med. 2005;352(6):596-607. doi:10.1056/NEJMcp042262.

2. Fabris P, Tositti G, Manfrin V, Giordani MT, Vaglia A, Cattelan AM, et al. Does alcohol intake affect highly active antiretroviral therapy (HAART) response in HIV-positive patients? I Acquir Immune Defic Syndr. 2000;25:92-3.

3. Cook RL, Sereika SM, Hunt SC, Woodward WC, Erlen JA, Conigliaro J. Problem drinking and medication adherence among persons with HIV infection. J Gen Intern Med. 2001;16:83-8.

4. Galvan FH, Bing EG, Fleishman JA, London AS, Caetano R, Burnam MA, et al. The prevalence of alcohol consumption and heavy drinking among people with HIV in the United States: results from the HIV cost and services utilization study. J Stud Alcohol. 2002;63:179-86.
5. Lucas GM, Gebo KA, Chaisson RE, Moore RD. Longitudinal assessment of the effects of drug and alcohol abuse on HIV-1 treatment outcomes in an urban clinic. Aids. 2002;16(5):767-74.

6. Samet JH, Horton NJ, Traphagen ET, Lyon SM, Freedberg KA. Alcohol consumption and HIV disease progression: are they related? Alcohol Clin Exp Res. 2003;27(5):862-7.

7. Arnsten JH, Demas PA, Grant RW, Gourevitch MN, Farzadegan H, Howard $A A$, et al. Impact of active drug use on antiretroviral therapy adherence and viral suppression in HIV-infected drug users. J Gen Int Med. 2002;17:377-81.

8. Williams EC, Bradley KA, Balderson BH, McClure JB, Grothaus L, McCoy K, et al. Alcohol and associated characteristics among older persons living with human immunodeficiency virus on antiretroviral therapy. Subst Abus. 2014;35(3):245-53. doi:10.1080/08897077.2014.890997.

9. Korthuis PT, Zephyrin LC, Fleishman JA, Saha S, Josephs JS, McGrath MM, et al. Health-related quality of life in HIV-infected patients: the role of substance use. AIDS Patient Care STDS. 2008;22(11):859-67.

10. Korthuis PT, Fiellin DA, McGinnis KA, Skanderson M, Justice AC, Gordon AJ, et al. Unhealthy alcohol and illicit drug use are associated with decreased quality of HIV care. J Acquir Immune Defic Syndr. 2012;61(2):171-8. doi:10.1097/QAl.0b013e31826741aa.

11. Freiberg MS, McGinnis KA, Kraemer K, Samet JH, Conigliaro J, Curtis Ellison R, et al. The association between alcohol consumption and prevalent cardiovascular diseases among HIV-infected and HIV-uninfected men. J Acquir Immune Defic Syndr. 2010;53(2):247-53. doi:10.1097/ QAl.0b013e3181c6c4b7.

12. Lim JK, Tate JP, Fultz SL, Goulet JL, Conigliaro J, Bryant KJ, et al. Relationship between alcohol use categories and noninvasive markers of advanced hepatic fibrosis in HIV-infected, chronic hepatitis C virusinfected, and uninfected patients. Clin Infect Dis. 2014;. doi:10.1093/cid/ ciu097.

13. McGinnis KA, Fultz SL, Skanderson M, Conigliaro J, Bryant K, Justice AC. Hepatocellular carcinoma and non-Hodgkin's lymphoma: the roles of HIV, hepatitis C infection, and alcohol abuse. J Clin Oncol. 2006;24(31):5005-9. doi:10.1200/JCO.2006.05.7984

14. Mayer KH, Skeer MR, O'Cleirigh C, Goshe BM, Safren SA. Factors associated with amplified hiv transmission behavior among american men who have sex with men engaged in care: implications for clinical providers. Ann Behav Med. 2013; doi:10.1007/s12160-013-9527-1.

15. Cook RL, McGinnis KA, Kraemer KL, Gordon AJ, Conigliaro J, Maisto $S A$, et al. Intoxication before intercourse and risky sexual behavior in male veterans with and without human immunodeficiency virus infection. Med Care. 2006;44(8 Suppl 2):S31-6. doi:10.1097/01. mlr.0000223710.35008.d9 00005650-200608002-00005 [pii]

16. Lefevre F, O'Leary B, Moran M, Mossar M, Yarnold PR, Martin GJ, et al. Alcohol consumption among HIV-infected patients. J Gen Intern Med. 1995;10(8):458-60.

17. Petry NM. Alcohol use in HIV patients: what we don't know may hurt us. Int J STD AIDS. 1999;10(9):561-70.

18. Cook RL, Sereika SM, Hunt SC, Woodward WC, Erlen JA, Conigliaro J. Problem drinking and medication adherence among persons with HIV infection. J Gen Intern Med. 2001;16(2):83-8.

19. Samet JH, Cheng DM, Libman H, Nunes DP, Alperen JK, Saitz R. Alcohol consumption and HIV disease progression. J Acquir Immune Defic Syndr. 2007:46(2):194-9. doi:10.1097/QAl.0b013e318142aabb.

20. Samet JH, Horton NJ, Traphagen ET, Lyon SM, Freedberg KA. Alcohol consumption and HIV disease progression: are they related? Alcohol Clin Exp Res. 2003;27(5):862-7. doi:10.1097/01.ALC.0000065438.80967.56.

21. Samet JH, Phillips SJ, Horton NJ, Traphagen ET, Freedberg KA. Detecting alcohol problems in HIV-infected patients: use of the CAGE questionnaire. AIDS Res Hum Retroviruses. 2004;20(2):151-5. doi:10.1089/088922204773004860.

22. Jonas DE, Garbutt JC, Amick HR, Brown JM, Brownley KA, Council $C L$, et al. Behavioral counseling after screening for alcohol misuse in primary care: a systematic review and meta-analysis for the US preventive services task force. Ann Intern Med. 2012; doi:10.7326/0003-4819-157-9-201211060-00544.

23. Anton RF, O'Malley SS, Ciraulo DA, Cisler RA, Couper D, Donovan DM, et al. Combined pharmacotherapies and behavioral interventions for alcohol dependence: the COMBINE study: a randomized controlled trial. JAMA. 2006;295(17):2003-17. doi:10.1001/jama.295.17.2003. 
24. Jonas DE, Amick HR, Feltner C, Bobashev G, Thomas K, Wines R, et al. Pharmacotherapy for adults with alcohol use disorders in outpatient settings: a systematic review and meta-analysis. JAMA. 2014;311(18):1889-900. doi:10.1001/jama.2014.3628.

25. Brown JL, DeMartini KS, Sales JM, Swartzendruber AL, DiClemente RJ. Interventions to reduce alcohol use among HIV-infected individuals: a review and critique of the literature. Curr HIV/AIDS Rep. 2013;10(4):35670. doi:10.1007/s11904-013-0174-8.

26. Hasin DS, Aharonovich E, O'Leary A, Greenstein E, Pavlicova M, Arunajadai $S$, et al. Reducing heavy drinking in HIV primary care: a randomized trial of brief intervention, with and without technological enhancement. Addiction. 2013;108(7):1230-40. doi:10.1111/add.12127.

27. Elliott JC, Aharonovich E, O'Leary A, Wainberg M, Hasin DS. Drinking motives as prospective predictors of outcome in an intervention trial with heavily drinking HIV patients. Drug Alcohol Depend. 2014;134:2905. doi:10.1016/j.drugalcdep.2013.10.026.

28. Elliott JC, Aharonovich E, O'Leary A, Wainberg M, Hasin DS. Drinking motives among HIV primary care patients. AIDS Behav. 2014;18(7):131523. doi:10.1007/s10461-013-0644-4.

29. Metsch LR, Pereyra M, Colfax G, Dawson-Rose C, Cardenas G, McKirnan D, et al. HIV-positive patients' discussion of alcohol use with their HIV primary care providers. Drug Alcohol Depend. 2008;95(1-2):37-44. doi:10.1016/j.drugalcdep.2007.12.006.

30. Conigliaro J, Gordon AJ, McGinnis KA, Rabeneck L, Justice AC. How harmful is hazardous alcohol use and abuse in HIV infection: do health care providers know who is at risk? J Acquir Immune Defic Syndr. 2003;33(4):521-5.

31. Conigliaro J, Justice AC, Gordon AJ, Bryant K. Role of alcohol in determining human immunodeficiency virus (HIV)-relevant outcomes: a conceptual model to guide the implementation of evidence-based interventions into practice. Med Care. 2006;44(8 Suppl 2):S1-6. doi:10.1097/01. mlr.0000223659.36369.cf.

32. Korthuis PT, Saha S, Chander G, McCarty D, Moore RD, Cohn JA, et al. Substance use and the quality of patient-provider communication in HIV clinics. AIDS Behav. 2011;15(4):832-41. doi:10.1007/s10461-010-9779-8.

33. Montague BT, Kahler CW, Colby SM, McHugh RK, Squires D, Fitzgerald B, et al. Attitudes and training needs of new england hiv care and addiction treatment providers: opportunities for better integration of hiv and alcohol treatment services. Addict Disord Their Treat. 2015;14(1):16-28. doi:10.1097/ADT.0000000000000040.

34. van Straten A, Hill J, Richards DA, Cuijpers P. Stepped care treatment delivery for depression: a systematic review and meta-analysis. Psychol Med. 2014;45:1-16. doi:10.1017/S0033291714000701.

35. James PA, Oparil S, Carter BL, Cushman WC, Dennison-Himmelfarb C, Handler J, et al. 2014 evidence-based guideline for the management of high blood pressure in adults: report from the panel members appointed to the Eighth Joint National Committee (JNC 8). JAMA. 2014;311(5):50720. doi:10.1001/jama.2013.284427.

36. National Institute on Alcohol Abuse and Alcoholism. What's "at-risk" or "heavy" drinking? http://rethinkingdrinking.niaaa.nih.gov/IsYourDrinkingPatternRisky/WhatsAtRiskOrHeavyDrinking.asp. Accessed 18 July 2011.

37. Sterling RK, Lissen E, Clumeck N, Sola R, Correa MC, Montaner J, et al. Development of a simple noninvasive index to predict significant fibrosis in patients with HIV/HCV coinfection. Hepatology. 2006;43(6):1317-25. doi:10.1002/hep.21178.

38. Mendeni M, Foca E, Gotti D, Ladisa N, Angarano G, Albini L, et al. Evaluation of liver fibrosis: concordance analysis between noninvasive scores (APRI and FIB-4) evolution and predictors in a cohort of HIVinfected patients without hepatitis $C$ and B infection. Clin Infect Dis. 2011;52(9):1164-73. doi:10.1093/cid/cir071.

39. American Psychiatric Association. Diagnostic and Statistical Manual of Mental Disorders (DSM-IV), fourth edition Washington. Washington: American Psychiatric Press; 1994.

40. D'Onofrio G, Pantalon MV, Degutis LC, Fiellin DA, O'Connor PG. Development and implementation of an emergency practitioner-performed brief intervention for hazardous and harmful drinkers in the emergency department. Acad Emerg Med. 2005;12(3):249-56. doi:10.1197/j. aem.2004.10.021.

41. Pantalon MV, Martino S, Dziura J, Li FY, Owens PH, Fiellin DA, et al. Development of a scale to measure practitioner adherence to a brief intervention in the emergency department. J Subst Abuse Treat. 2012;43(4):382-8. doi:10.1016/j.jsat.2012.08.011.

42. D'Onofrio G, Fiellin DA, Pantalon MV, Chawarski MC, Owens PH, Degutis $L C$, et al. A brief intervention reduces hazardous and harmful drinking in emergency department patients. Ann Emerg Med. 2012;. doi:10.1016/j. annemergmed.2012.02.006.

43. Miller WR, Zweben A, DiClememte CC, Rycharik RG. Motivational enhancement therapy manual: a clinical research guide for therapists treating individuals with alcohol abuse and dependence, NIAAA Project MATCH Monograph. 1992. http://pubs.niaaa.nih.gov/publications/ProjectMatch/match02.pdf. Accessed 1 Jan 2015

44. Justice AC, McGinnis KA, Skanderson M, Chang CC, Gibert CL, Goetz $M B$, et al. Towards a combined prognostic index for survival in HIV infection: the role of 'non-HIV' biomarkers. HIV Med. 2010;11(2):143-51. doi:10.1111/j.1468-1293.2009.00757.x.

45. Justice AC, Modur SP, Tate JP, Althoff KN, Jacobson LP, Gebo KA, et al Predictive accuracy of the veterans aging cohort study index for mortality with HIV infection: a North American cross cohort analysis. J Acquir Immune Defic Syndr. 2013;62(2):149-63. doi:10.1097/ QAl.0b013e31827df36c.

46. Tate JP, Justice AC, Hughes MD, Bonnet F, Reiss P, Mocroft A, et al. An internationally generalizable risk index for mortality after 1 year of antiretroviral therapy. AIDS. 2013;27(4):563-72. doi:10.1097/ QAD.0b013e32835b8c7f.

47. Rosland AM, Nelson K, Sun H, Dolan ED, Maynard C, Bryson C, et al. The patient-centered medical home in the Veterans Health Administration. Am J Manag Care. 2013;19(7):e263-72.

48. Kearney LK, Post EP, Zeiss A, Goldstein MG, Dundon M. The role of mental and behavioral health in the application of the patient-centered medical home in the department of veterans affairs. Transl Behav Med. 2011;1(4):624-8. doi:10.1007/s13142-011-0093-4.

49. Curran GM, Bauer M, Mittman B, Pyne JM, Stetler C. Effectiveness-implementation hybrid designs: combining elements of clinical effectiveness and implementation research to enhance public health impact. Med Care. 2012;50(3):217-26. doi:10.1097/MLR.0b013e3182408812.

50. McGovern MP, Saunders EC, Kim E. Substance abuse treatment implementation research. J Subst Abuse Treat. 2013;44(1):1-3. doi:10.1016/j. jsat.2012.09.006.

51. Green CA, McCarty D, Mertens J, Lynch FL, Hilde A, Firemark A, et al. A qualitative study of the adoption of buprenorphine for opioid addiction treatment. J Subst Abuse Treat. 2014;46(3):390-401. doi:10.1016/j. jsat.2013.09.002

52. Hartzler B, Lash SJ, Roll JM. Contingency management in substance abuse treatment: a structured review of the evidence for its transportability. Drug Alcohol Depend. 2012;122(1-2):1-10. doi:10.1016/j. drugalcdep.2011.11.011.

53. Damschroder $L J$, Hagedorn HJ. A guiding framework and approach for implementation research in substance use disorders treatment. Psychol Addict Behav. 2011;25(2):194-205. doi:10.1037/a0022284.

54. Damschroder LJ, Aron DC, Keith RE, Kirsh SR, Alexander JA, Lowery JC. Fostering implementation of health services research findings into practice: a consolidated framework for advancing implementation science. Implement Sci. 2009;4:50. doi:10.1186/1748-5908-4-50.

55. Curry LA, Nembhard IM, Bradley EH. Qualitative and mixed methods provide unique contributions to outcomes research. Circulation. 2009;119(10):1442-52

56. Hsieh HF, Shannon SE. Three approaches to qualitative content analysis. Qual Health Res. 2005;15(9):1277-88. doi:10.1177/1049732305276687.

57. Elo $S$, Kyngas $H$. The qualitative content analysis process. J Adv Nurs. 2008;62(1):107-15. doi:10.1111/j.1365-2648.2007.04569.x.

58. Fredriksson M, Eldh A, Vengberg S, Dahlstrom T, Halford C, Wallin L, et al. Local politico-administrative perspectives on quality improvement based on national registry data in Sweden: a qualitative study using the consolidated framework for implementation research. Implement Sci. 2014;9(1):777. doi:10.1186/s13012-014-0189-6.

59. Damschroder LJ, Lowery JC. Evaluation of a large-scale weight management program using the consolidated framework for implementation research (CFIR). Implement Sci. 2013;8:51. doi:10.1186/1748-5908-8-51.

60. Murphy K, O'Connor DA, Browning CJ, French SD, Michie S, Francis JJ, et al. Understanding diagnosis and management of dementia and guideline implementation in general practice: a qualitative study 
using the theoretical domains framework. Implement Sci. 2014;9:31. doi:10.1186/1748-5908-9-31.

61. Bergstrom A, Peterson S, Namusoko S, Waiswa P, Wallin L. Knowledge translation in Uganda: a qualitative study of Ugandan midwives' and managers' perceived relevance of the sub-elements of the context cornerstone in the PARIHS framework. Implement Sci. 2012;7:117. doi:10.1186/1748-5908-7-117.

62. Barry DT, Irwin KS, Jones ES, Becker WC, Tetrault JM, Sullivan LE, et al. Opioids, chronic pain, and addiction in primary care. J Pain. 2010;11(12):1442-50. doi:10.1016/j.jpain.2010.04.002.

63. Barry DT, Irwin KS, Jones ES, Becker WC, Tetrault JM, Sullivan LE, et al. Integrating buprenorphine treatment into office-based practice: a qualitative study. J Gen Intern Med. 2009;24(2):218-25. doi:10.1007/ s11606-008-0881-9.

64. Hieftje K, Rosenthal MS, Camenga DR, Edelman EJ, Fiellin LE. A qualitative study to inform the development of a video game for adolescent HIV prevention. Games Health J. 2012;1(4):294-8. doi:10.1089/g4h.2012.0025.

65. Edelman EJ, Cole CA, Richardson W, Boshnack N, Jenkins H, Rosenthal MS. Opportunities for improving partner notification for HIV: results from a community-based participatory research study. AIDS Behav. 2014;. doi:10.1007/s10461-013-0692-9.

66. Maisto SA, Carey KB, Carey MP, Purnine DM, Barnes KL. Methods of changing patterns of substance use among individuals with co-occurring schizophrenia and substance use disorder. J Subst Abuse Treat. 1999;17(3):221-7.

67. Noel NE, Ogle RL, Maisto SA, Jackson LA Jr. What Do Women Want? A qualitative study of dating. Violence Against Women. 2014; doi:10.1177/1077801214555472.

68. Fox AM, Jackson SS, Hansen NB, Gasa N, Crewe M, Sikkema KJ. In their own voices: a qualitative study of women's risk for intimate partner violence and HIV in South Africa. Violence Against Women. 2007;13(6):583602. doi:10.1177/1077801207299209.

69. Crabtree BF, Miller WL. Doing Qualitative Research. 2nd edn. Thousand Oaks: Sage Publications; 1999.

70. Elliott JC, Aharonovich E, Hasin DS. Reasons for limiting drinking in an HIV primary care sample. Alcohol Clin Exp Res. 2014;38(6):1720-7. doi:10.1111/acer.12401.

71. Bradley KA, Williams EC, Achtmeyer CE, Volpp B, Collins BJ, Kivlahan DR. Implementation of evidence-based alcohol screening in the Veterans Health Administration. Am J Manag Care. 2006;12(10):597-606.
72. Williams EC, Rubinsky AD, Chavez L, Lapham GT, Rittmueller SE, Achtmeyer CE, et al. An early evaluation of implementation of brief intervention for unhealthy alcohol use in the US veterans health administration. Addiction. 2014;109(9):1472-81. doi:10.1111/add.12600.

73. Iheanacho T, Issa M, Marienfeld C, Rosenheck R. Use of naltrexone for alcohol use disorders in the Veterans' Health Administration: a national study. Drug Alcohol Depend. 2013;132(1-2):122-6. doi:10.1016/j. drugalcdep.2013.01.016

74. Marienfeld C, Iheanacho T, Issa M, Rosenheck RA. Long-acting injectable depot naltrexone use in the Veterans' Health Administration: a national study. Addict Behav. 2014;39(2):434-8. doi:10.1016/j.addbeh.2013.05.006.

75. Del Re AC, Gordon AJ, Lembke A, Harris AH. Prescription of topiramate to treat alcohol use disorders in the veterans health administration. Addict Sci Clin Pract. 2013;8:12. doi:10.1186/1940-0640-8-12.

76. Group; TMOSUDW. VA/DoD Clinical practice guideline for management of Substance Use Disorders (SUD). In: Department of veterans affairs DoD. 2009.

77. Bradley KA, Kivlahan DR. Bringing patient-centered care to patients with alcohol use disorders. JAMA. 2014;311(18):1861-2. doi:10.1001/ jama.2014.3629.

78. Korthuis PT, Josephs JS, Fleishman JA, Hellinger J, Himelhoch S, Chander $\mathrm{G}$, et al. Substance abuse treatment in human immunodeficiency virus: the role of patient-provider discussions. J Subst Abuse Treat. 2008;35(3):294-303. doi:10.1016/j.jsat.2007.11.005.

79. Fiellin DA, Weiss L, Botsko M, Egan JE, Altice FL, Bazerman LB, et al. Drug treatment outcomes among HIV-infected opioid-dependent patients receiving buprenorphine/naloxone. J Acquir Immune Defic Syndr. 2011;56(Suppl 1):S33-8. doi:10.1097/QAl.0b013e3182097537.

80. Korthuis PT, Fiellin DA, Fu R, Lum PJ, Altice FL, Sohler N, et al. Improving adherence to HIV quality of care indicators in persons with opioid dependence: the role of buprenorphine. J Acquir Immune Defic Syndr. 2011;56(Suppl 1):S83-90. doi:10.1097/QAl.0b013e31820bc9a5.

81. Drainoni ML, Farrell C, Sorensen-Alawad A, Palmisano JN, Chaisson C, Walley AY. Patient perspectives of an integrated program of medical care and substance use treatment. AIDS Patient Care STDS. 2014;28(2):71-81. doi:10.1089/apc.2013.0179.

\section{Submit your next manuscript to BioMed Central and we will help you at every step:}

- We accept pre-submission inquiries

- Our selector tool helps you to find the most relevant journal

- We provide round the clock customer support

- Convenient online submission

- Thorough peer review

- Inclusion in PubMed and all major indexing services

- Maximum visibility for your research

Submit your manuscript at www.biomedcentral.com/submit

\section{Biomed Central}

